\title{
COMPARISON OF TEMPERATURE AND OXYGEN CONCENTRATION DRIVEN AERATION METHODS FOR BIODRYING OF MUNICIPAL SOLID WASTE
}

\author{
VOJTĚCH PILNÁČEK*, LIBUŠE BENEŠOVÁ, TOMÁŠ CAJTHAML, \\ and PETRA INEMANNOVÁ
}

Institute for Environmental Studies, Faculty of Science, Charles University in Prague, Benátská 2, 128 01, Prague 2, Czech Republic

* Corresponding author: Vojtech.Pilnacek@gmail.com

\begin{abstract}
In this study, we used a model bio drying reactor to optimize the drying of municipal solid waste (MSW). Two methods of aeration were used: one involved controlling the concentration of oxygen (16-20\%) and the other the temperature in the upper part of the reactor (temperature $42-45^{\circ} \mathrm{C}$, oxygen concentration 16-20\%). In terms of moisture content, the highest increase recorded was $0.94 \%$ and the highest decrease was $27.54 \%$. The highest decrease in lower calorific value recorded was $9.23 \%$ and the highest increase was $41.12 \%$. The energy balance in all the trial runs was positive. We noted that aeration using different concentrations of oxygen is strongly influenced by organic content. Thus, it is suitable only for drying wastes with known and stable compositions. The outcomes of the different methods used were influenced by ambient relative air humidity. Moisture gradients, which are often described in the literature, were not consistently reproduced in this study.
\end{abstract}

Keywords: aeration method; ambient moisture; bio drying; mechanical-biological treatment; municipal solid waste; organic content

\section{Introduction}

Bio drying is a process that utilises heat generated by aerobic decomposition of organic matter for drying substrates. The principal of the entire process lies in the air that is blown into the substrate, which is a source of oxygen for aerobic decomposition processes and a means of venting evaporated moisture. However, it also simultaneously cools the medium and negatively affects the energetic balance of the process. The main purpose of bio drying is to obtain a fuel with a high calorific value (Velis et al. 2009). Thus, it is necessary to determine optimal conditions for achieving a suitably dry substrate with the lowest energy consumption and lowest decomposition of organic matter. One of the main factors affecting this is the rate of aeration.

Rate of aeration was studied by Adani et al. (2002), who report that optimal drying efficiency can be achieved by using higher rates of aeration, which result in lower temperatures in the reactor chamber. Similar results are reported by Zhao et al. (2010), Cai et al. (2013), Yuan et al. (2018) and Zhang et al. (2020). The highest rate of aeration resulted in the highest evaporation, lowest decomposition of organic matter and highest calorific value of residue. The higher the rate of aeration, the greater the loss of moisture. However, when the substrate dries out, the microorganisms that decompose the organic matter suffer from a lack of water and become inactive (Walker et al. 1999; Adani et al. 2002; Avalos Ramirez et al. 2012). Huiliñir and Villegas (2014) report, that very high rates of aeration dries out and cools down the substrate and decreases the rate of decomposition of organic matter. Then the moisture content can be further decreased, but the convection drying effect is stronger than the bio drying effect. On the other hand, Vandergheynst et al. (1997) report that when the rate of aeration is too low there is a deficit of oxygen in the upper parts of the substrate, which results in a decrease in the activity of microorganisms.

In addition, the studies using high rates of aeration also indicate there are gradients in temperature, moisture and calorific value in the reactor chamber (Adani et al. 2002; Sugni et al. 2005; Zhao et al. 2010), which results in the final substrate/fuel not being homogeneous in terms of quality.

The aim of this study was to compare two methods of aeration in order to determine the optimal rate. The two methods of aeration tested was one in which the oxygen concentration was controlled (as in industrial applications, e.g. Comptech biodrying system) and another in which temperature is controlled in the upper part of the reactor. Drying efficiency (decrease in moisture content, increase in calorific value), energy balance and occurrence of gradients recorded for these two methods were compared.

\section{Material and Methods}

\section{Mixed solid waste (MSW) sample}

A sample consisting of $1 \mathrm{~m}^{3}$ was collected from the regular MSW of the town Mníšek pod Brdy in the Czech Republic, which is the site of a proposed mechanical-biological waste treatment facility. Metal, glass and other rigid materials that could damage the equipment used in the subsequent grinding of the waste were removed. The sample was shredded using a grinder until the grain size was approximately $30 \mathrm{~mm}$. The quartering method was used to obtain a $30 \mathrm{~kg}$ subsample for this study. This subsample was transported in a plastic barrel directly to the laboratory. A second $1 \mathrm{~kg}$ subsample was used for de- 
Table 1 Composition of the substrate in the different treatments.

\begin{tabular}{|l|c|c|c|}
\hline Treatment & $\begin{array}{c}\text { Plastics } \\
\text { (\%) }\end{array}$ & $\begin{array}{c}\text { Biodegradable } \\
\text { (\%) }\end{array}$ & Textile (\%) \\
\hline Temperature 1 & 26.4 & 59.7 & 13.9 \\
\hline Temperature 2 & 24.2 & 48.7 & 12.1 \\
\hline Oxygen 1 & 21.4 & 65.2 & 13.4 \\
\hline Oxygen 2 & 24.6 & 70.9 & 4.5 \\
\hline
\end{tabular}

termining moisture content, calorific value and volatile matter content. Composition of the MSW sample is described in Table 1.

\section{Model reactor}

The reactor designed specifically for this study, consisted of a reactor chamber, a Secoh SLL 50 blower and a biofilter. The chamber of the reactor consisted of a $120 \mathrm{~cm}$ PVC cylinder with an internal diameter of $40 \mathrm{~cm}$. A $3 \mathrm{~mm}$ mesh sieve was placed above the bottom of the reactor chamber to stabilise the waste and disperse the air supply. Below the sieve, there was a $10 \mathrm{~cm}$ layer of $5 \mathrm{~mm}$ glass beads to facilitate the removal of any leachate, which then drains out of the bottom of the reactor into an air-tight Erlenmeyer flask. The air inlet was above the bottom in the drainage layer and the exhaust vent in the lid of the chamber. The entire reactor was enclosed in a $10 \mathrm{~cm}$ thick layer of insulating material. Probes for sampling and measuring experimental conditions during the process were installed within the reactor walls. Papouch THT2 temperature and oxygen probes were placed in the upper and lower air passages. An ASEKO GTE oxygen sensor was placed under the reactor lid. In order to adjust the flow rate, we used an electronically-controlled blower. The reactor was connected to other parts of the system by plastic tubing. To determine the ambient temperature and humidity in the system, an external thermometer and hygrometer Papouch THT2 were attached to the reactor assembly about $0.5 \mathrm{~m}$ from the air inlet. These sensors were connected to a computer via signal converters. The blower was operated by a USB I/O module Papouch Quido 2/2. A multi-range BK G4 $\mathrm{BO}$ diaphragm gas meter was connected to the blower and the reactor chamber in order to measure the total volume of air that passed through the chamber (Fig. 1).

\section{Aeration}

The waste was dried using two methods of aeration: one by controlling the concentration of oxygen and the other by controlling the temperature in the upper part of the reactor.

During the run when the concentration of oxygen was controlled, the concentration in the upper part of the reactor was between $16 \%$ and $20 \%$. When oxygen concentration fell below $16 \%$ or rose above $20 \%$, the blower was turned on or off, respectively. According to Avalos Ramirez et al. (2012) an optimum oxygen concentration

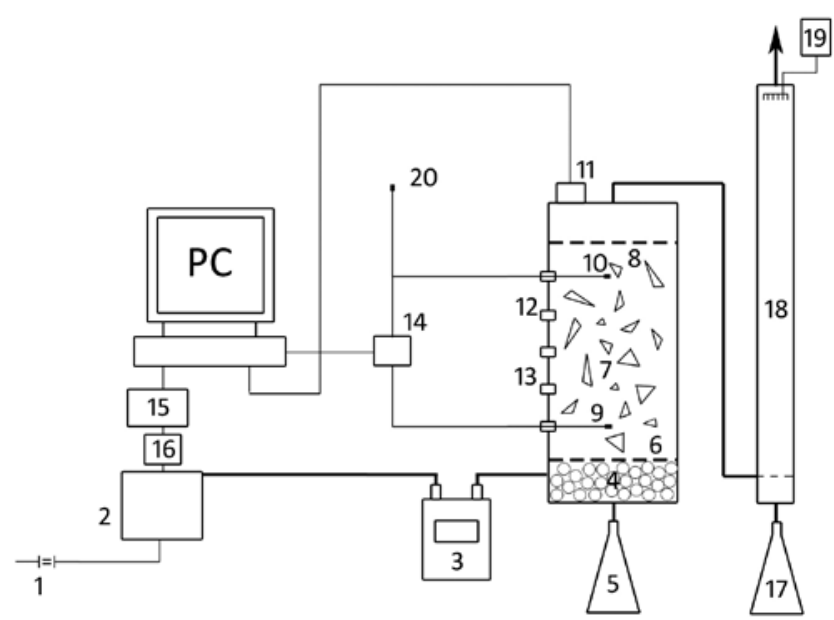

Fig. 1 Diagram of the reactor.

1 - Voltage regulator, 2 - Air source, 3 - Gas meter, 4 - Drainage layer, 5 - Erlenmeyer flask to drain leachate, 6 - Perforated sheet, 7 - Dried waste, 8 - Perforated sheet, 9 - Temperature and moisture meters, 10 - Temperature and moisture meters, 11 - Oxygen sensor, 12 - Port for sampling, 13 - Port for sampling, 14 - PC converter, 15 - USB I/O module for switching the air source, 16 - Relay for switching the air source, 17 - Erlenmeyer flask for collecting condensate, 18 - Biofilter (compost, peat, bark, expanded clay), 19 - The nutrient solution needed for the proper functioning of the biofilter (odour control), 20 - Ambient air temperature and moisture meters.

for aerobic degradation is between $15 \%$ and $20 \%$. During drying, temperature and relative humidity were recorded in the upper and lower layer. The oxygen concentration in the upper part of the reactor was recorded, as were the ambient temperature and moisture outside the reactor. The oxygen concentration in the upper layer, the moisture and temperature were recorded at five second intervals and the activity of the blower was recorded at one second intervals. The measurements were taken with a Papouch THT2 sensor and ASEKO GTE oxygen sensor using Wix software. The data processing was done using Microsoft Excel and R.

During the run in which the temperature in the upper part of the reactor was controlled, the blower was turned on when the temperature in the upper layer reached $45^{\circ} \mathrm{C}$ and switched off when it decreased to $42{ }^{\circ} \mathrm{C}$. The upper temperature limit is based on the study of Adani et al. (2002). In addition, the oxygen concentration in the upper layer was maintained, as mentioned above, in the range $16 \%$ to $20 \%$ (Table 2).

\section{Product collection and processing}

There was four drying runs: two in which temperature was controlled and two in which the concentration of oxygen was controlled. The runs took from 253 to 259 hours. After every run, using the openings in the reactor, samples were taken from the upper and lower layer to analyse the drying efficiency. The weight of each sample was approximately $1 \mathrm{~kg}$. Each sample was tested for moisture content, volatile matter content and calorific value. 
Table 2 Conditions in reactor.

\begin{tabular}{|l|c|c|c|c|c|}
\hline Run & Waste mass $(\mathbf{k g})$ & Time $(\mathbf{h})$ & Air consumption $\left(\mathbf{m}^{\mathbf{3}}\right)$ & Air flow before (I/s) & Air flow after (I/s) \\
\hline Temperature 1 & 30.0 & 257.50 & 538.707 & 78 \\
\hline Temperature 2 & 32.9 & 259.37 & 408.599 & 72 \\
\hline Oxygen 1 & 30.0 & 253.33 & 76.079 & 72 \\
\hline Oxygen 2 & 30.0 & 258.98 & 119.248 & 71 \\
\hline
\end{tabular}

To determine moisture content, three samples weighing $150-200 \mathrm{~g}$ were dried to a constant weight at $105^{\circ} \mathrm{C}$ and then gravimetrically analysed.

To determine volatile matter content, three $500 \mathrm{~g}$ subsamples were pre-dried at room temperature for 48 hours and then ground to a $1 \mathrm{~mm}$ grain size using a Retsch mill. The percentage of volatile matter in the resulting sample was determined. Three $1 \mathrm{~g}$ test samples obtained after annealing the material in an oven $\left(850^{\circ} \mathrm{C}, 7\right.$ minutes, in a closed porcelain crucible) were gravimetrically analysed.

To determine the calorific value using the heat of combustion, three $1 \mathrm{~g}$ samples were analysed using an IKA Werke C2000 unit according to the technical norm ČSN EN 15400 Solid recovered fuels - Determination of calorific value.

\section{Energy balance}

The energy balance of the process was calculated as follows:

$$
E=\left(H_{\text {after }} \cdot m_{\text {after }}\right)-\left(H_{\text {before }} \cdot m_{\text {before }}\right)-P \cdot t
$$

where $E$ - energy balance, $H_{\text {after }}$ - calorific value after drying, $H_{\text {before }}$ - calorific value before drying, $m_{\text {waste }}$ mass of dried waste, $P$ - air supply wattage $(65 \mathrm{~W}), t$ - air supply function time.

\section{Results and Discussion}

\section{Removal of water}

Moisture contents were in accordance with the relative air humidity in the upper and lower layers in both methods. The largest decrease in moisture content was recorded when temperature was controlled in run No. 2, when in the lower layer it decreased by $27.54 \%$. This is in accordance with Adani et al. (2002) and Sugni et al. (2005). The moisture content in the upper layer varied by about $10 \%$ from that recorded in the lower layer.

When the oxygen concentration was controlled the drying efficiency was the lowest. In fact, we even recorded a rise in moisture content in the upper layer. This was a result of water condensing on the ceiling of the reactor. Condensation occurred in all runs due to the low level of aeration, but in this run it was particularly marked (Table 3). These results are consistent with those of De Guardia et al. (2012).

\section{Calorific value}

The biggest change in the calorific value was recorded in run No. 1, in which temperature was controlled, which was because it was well aerated, little decomposition of organic matter and the low relative air humidity in the

Table 3 Values of moisture before and after the runs.

\begin{tabular}{|l|c|c|c|c|c|}
\hline Run & $\begin{array}{c}\text { Moisture before } \\
\text { (\%) }\end{array}$ & $\begin{array}{c}\text { Moisture after } \\
\text { in upper layer (\%) }\end{array}$ & $\begin{array}{c}\text { Moisture after } \\
\text { in lower layer (\%) }\end{array}$ & $\begin{array}{c}\text { Desiccation } \\
\text { of upper layer (\%) } \\
\text { of lower layer (\%) }\end{array}$ \\
\hline Temperature 1 & $41.80 \pm 1.88$ & $23.87 \pm 3.20$ & $13.74 \pm 2.79$ & 27.54 & 17.41 \\
\hline Temperature 2 & $43.64 \pm 1.16$ & $25.08 \pm 0.65$ & $22.87 \pm 1.60$ & 18.56 & -0.94 \\
\hline Oxygen 1 & $36.88 \pm 1.61$ & $37.82 \pm 2.12$ & $21.76 \pm 0.65$ & 16.12 \\
\hline Oxygen 2 & $38.52 \pm 1.26$ & $15.81 \pm 0.43$ & 22.77 & 2.80 & 2.71 \\
\hline
\end{tabular}

$a=95 \%$

Table 4 Calorific value before and after the process.

\begin{tabular}{|l|c|c|c|c|c|}
\hline Run & $\begin{array}{c}\text { LCV before } \\
\text { (MJ/t) }\end{array}$ & $\begin{array}{c}\text { LCV after } \\
\text { in upper layer (MJ/t) }\end{array}$ & $\begin{array}{c}\text { LCV after } \\
\text { in lower layer (MJ/t) }\end{array}$ & $\begin{array}{c}\text { LCV change } \\
\text { in upper layer (\%) }\end{array}$ & $\begin{array}{c}\text { LCV change } \\
\text { in lower layer (\%) }\end{array}$ \\
\hline Temperature 1 & $9,077.12 \pm 73.78$ & $13,818.18 \pm 344.23$ & $15,415.33 \pm 253.22$ & 34.31 & 27.74 \\
\hline Temperature 2 & $9,835.66 \pm 21.21$ & $13,610.96 \pm 772.26$ & $14,817.38 \pm 668.71$ & 33.62 & -9.23 \\
\hline Oxygen 1 & $12,358.60 \pm 219.74$ & $11,314.05 \pm 51.51$ & $14,548.64 \pm 95.82$ & 15.05 & 34.70 \\
\hline Oxygen 2 & $11,102.23 \pm 123.71$ & $14,982.44 \pm 197.09$ & $17,001.06 \pm 180.99$ & \\
\hline
\end{tabular}

LCV - Lower calorific value, $a=95 \%$ 
Table 5 Energetic balance of the process.

\begin{tabular}{|l|c|c|c|c|c|}
\hline Run & $\begin{array}{c}\text { Air supply } \\
\text { operational time (s) }\end{array}$ & $\begin{array}{c}\text { Energy } \\
\text { consumed (MJ) }\end{array}$ & $\begin{array}{c}\text { LCV average } \\
\text { before drying (MJ/t) }\end{array}$ & $\begin{array}{c}\text { LCV average } \\
\text { after drying (MJ/t) }\end{array}$ & $\begin{array}{c}\text { Energetic } \\
\text { balance (MJ) }\end{array}$ \\
\hline Temperature 1 & 439,338 & 28.12 & 9,077 & 14,617 & 138.07 \\
\hline Temperature 2 & 342,441 & 21.92 & 9,836 & 14,214 & 122.14 \\
\hline Oxygen 1 & 64,231 & 4.11 & 12,359 & 12,931 & 13.07 \\
\hline Oxygen 2 & 101,854 & 6.52 & 11,102 & 15,992 & 140.17 \\
\hline
\end{tabular}

LCV - Lower calorific value

laboratory. For details, see Table 5 and Fig. 2. Similar results are reported by Adani et al. (2002) and Sugni et al. (2005).

In run No. 1, in which the concentration of oxygen was controlled, we recorded the smallest change in the calorific value and it even a decrease in the upper layer. This was, as mentioned previously, due to the significant condensation on the ceiling of the reactor. Similarly, a minor change in calorific value was recorded in the lower layer. As the rate of aeration was very low its drying effect was low.

\section{Energetic balance}

The best energetic balance was recorded in run No. 2, in which the oxygen concentration was controlled. This was due to a high calorific value and a significantly lower energy consumption than in the other runs. A very similar energetic balance was recorded when the temperature was controlled in run No. 1. When the temperature was controlled in run No. 2, the energetic balance was slightly worse than in the previously mentioned runs since the drying efficiency was lower and energy consumption higher. The worst energetic balance was recorded when the concentration of oxygen was controlled in run No. 1, due to a very high level of condensation (Table 4).

Both of the methods resulted in a positive yielded of energy. This means that even though some energy was used for drying, when burned, the dry waste produced more energy than when untreated waste was incinerated. Similar results were obtained by Cimpan and Wenzel (2013) and Economopoulos (2010).

\section{Effect of ambient moisture}

In the method in which temperature was controlled, the drying efficiency recorded in run No. 1 and run No. 2 differed. In run No. 1, the moisture decreased from $41.28 \pm 1.88 \%$ to $23.87 \pm 3.20 \%$ in the upper layer and to $13.74 \pm 2.79 \%$ in the lower layer. In run No. 2 , the moisture decreased from $43.64 \pm 1.16 \%$ to $25.08 \pm 0.65 \%$ in the upper layer and to $22.87 \pm 1.60 \%$ in lower layer. The difference in drying efficiency was due to the difference in ambient air humidity (see Fig. 2). Apart from our study, the effect of ambient air humidity is mentioned only in one of the other studies on bio drying. Colomer-Mendoza et al. (2012) state that ambient air humidity, partic- ularly the humidity of the air entering the reactor determines the efficiency of drying.

\section{Spatial differences in temperature, moisture level and calorific value}

The recordings depicted in Figs 3, 4, 5 and 6 reveal a big difference in temperature in the lower and upper layer in the reactor. This is well described by Adani et al. (2002) and Sugni et al. (2005) and is attributed to the lower part of the reactor being cooled by the surrounding air. This difference was recorded in all of the runs.

The literature indicates there is also a difference in the moisture content. This is due to differences in the drying efficiency in the lower and upper layers of the reactor (Table 3) as previously reported by Adani et al. (2002), Sugni et al. (2005) and Zhao et al. (2010). The difference can be explained by the fact that the moisture in the upper layer of the reactor is not removed as efficiently by the air supplied from the surroundings as it is in the lower layer. The recordings in Figs 3, 5 and 6 support this explanation. In general, there was a lower relative humidity in the lower layer than in the upper layer of the reactor. An exception is shown in Fig. 4, (method in which the concentration of oxygen was controlled, run No. 2), when the relative

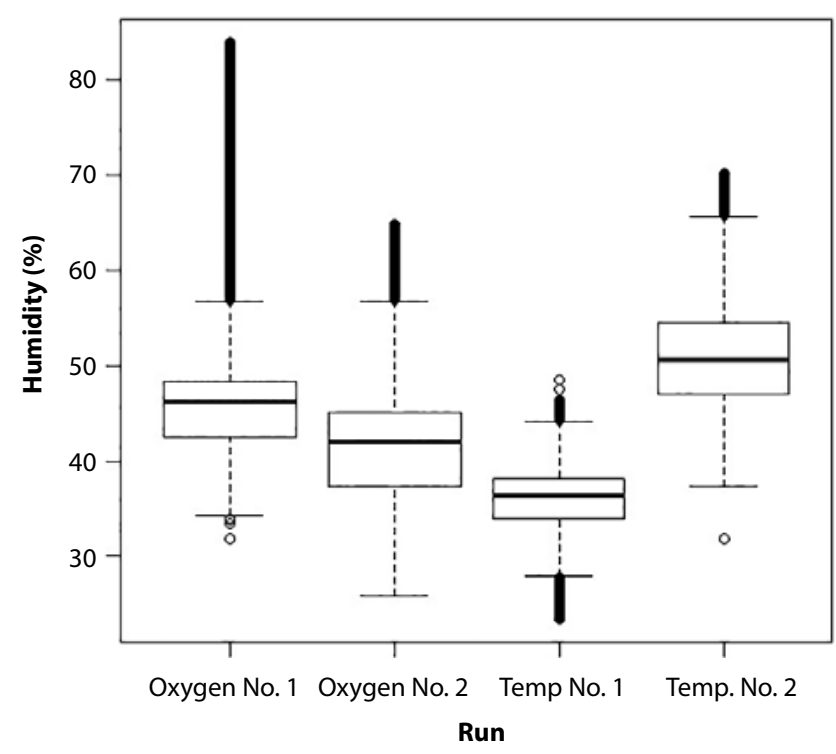

Fig. 2 Ambient air humidity recorded in the different runs. 


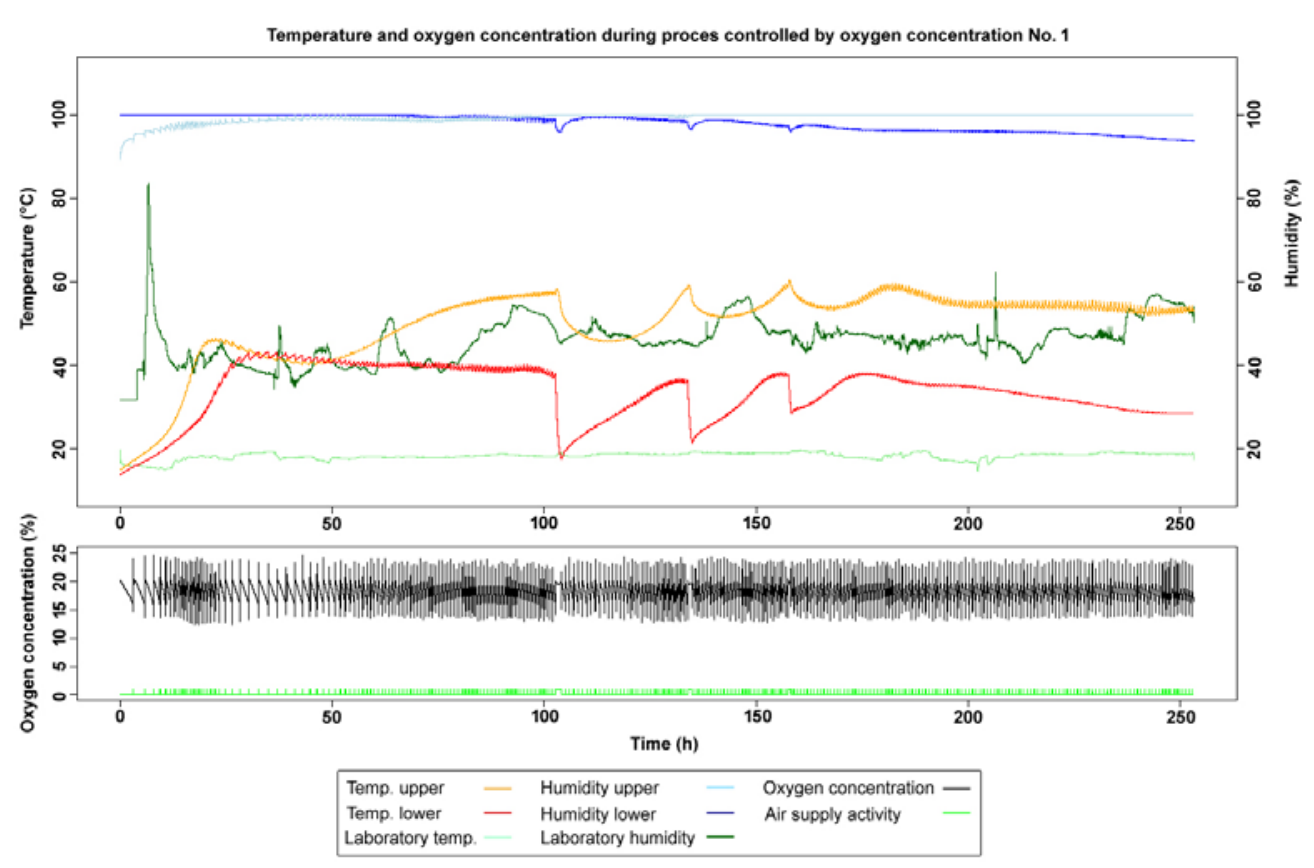

Fig. 3 Temporal dependence of the temperature, relative air humidity and oxygen level measured in the reactor and/or in the lab, temporal dependence of the air supply activity - method in which the concentration of oxygen was controlled, run No. 1.

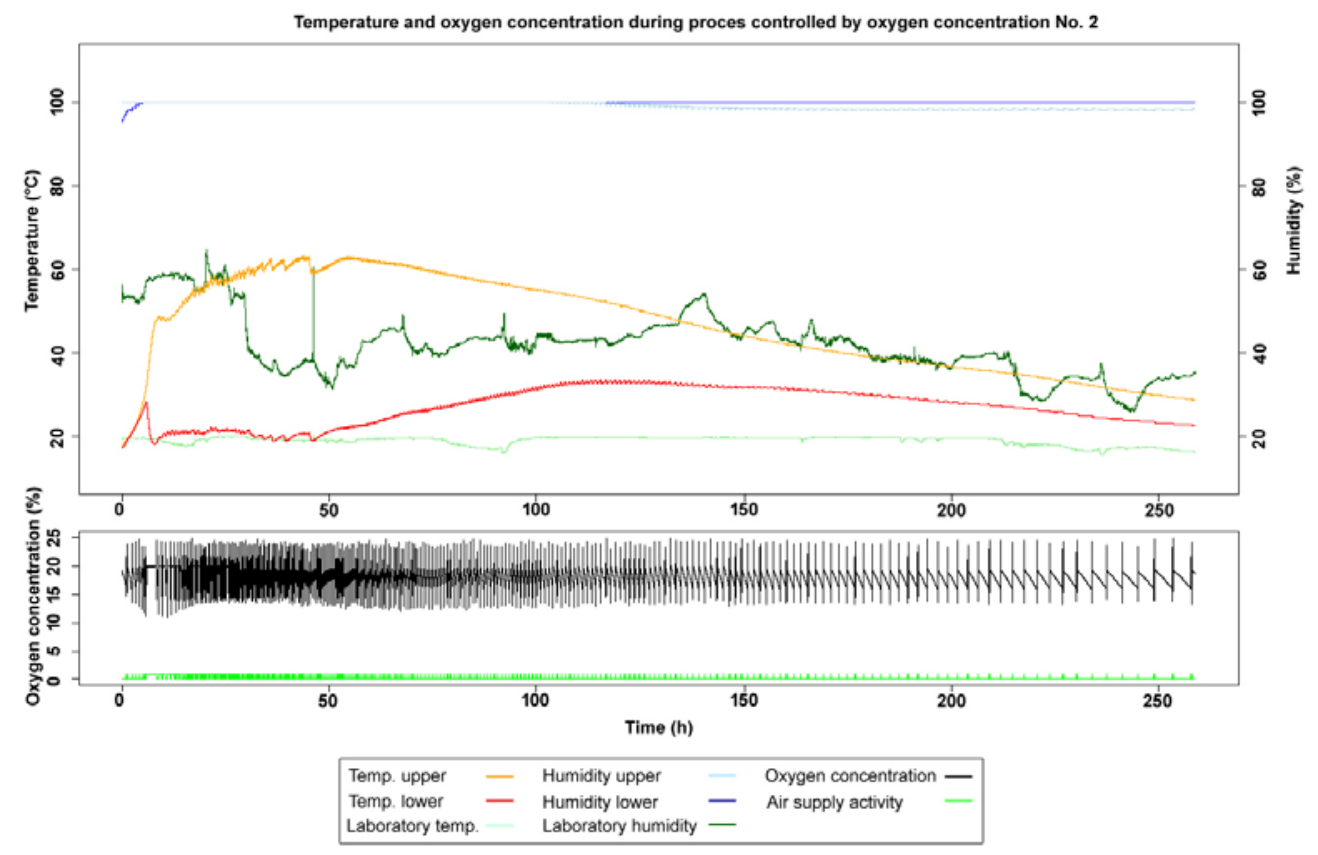

Fig. 4 Temporal dependence of the temperature, relative air humidity and oxygen level measured in the reactor and/or in the lab, temporal dependence of the air supply activity - method in which the concentration of oxygen was controlled, run No. 2.

Table 6 Changes in volatile matter content.

\begin{tabular}{|l|c|c|c|c|c|}
\hline Run & $\begin{array}{c}\text { Initial volatile } \\
\text { matter content (\%) }\end{array}$ & $\begin{array}{c}\text { Final volatile } \\
\text { matter content in } \\
\text { upper layer (\%) }\end{array}$ & $\begin{array}{c}\text { Final volatile } \\
\text { matter content in } \\
\text { lower layer (\%) }\end{array}$ & $\begin{array}{c}\text { Change in vol. } \\
\text { matt. in upper } \\
\text { layer (\%) }\end{array}$ & $\begin{array}{c}\text { Change in vol. } \\
\text { matt. in lower } \\
\text { layer (\%) }\end{array}$ \\
\hline Temperature 1 & $63.24 \pm 0.80$ & $65.04^{*}$ & $65.44 \pm 1.13$ & 1.80 & 2.20 \\
\hline Temperature 2 & $69.04 \pm 0.45$ & $68.31 \pm 0.42$ & $68.25 \pm 0.37$ & -0.73 & -0.79 \\
\hline Oxygen 1 & $63.85 \pm 0.42$ & $70.73 \pm 0.13$ & $69.75 \pm 0.44$ & 6.88 & 5.90 \\
\hline Oxygen 2 & $68.64 \pm 1.06$ & $66.32 \pm 0.80$ & $70.78 \pm 0.90$ & -2.32 & 2.14 \\
\hline
\end{tabular}

* based on only one measurement, $a=95 \%$

European Journal of Environmental Sciences, Vol. 11, №. 1 


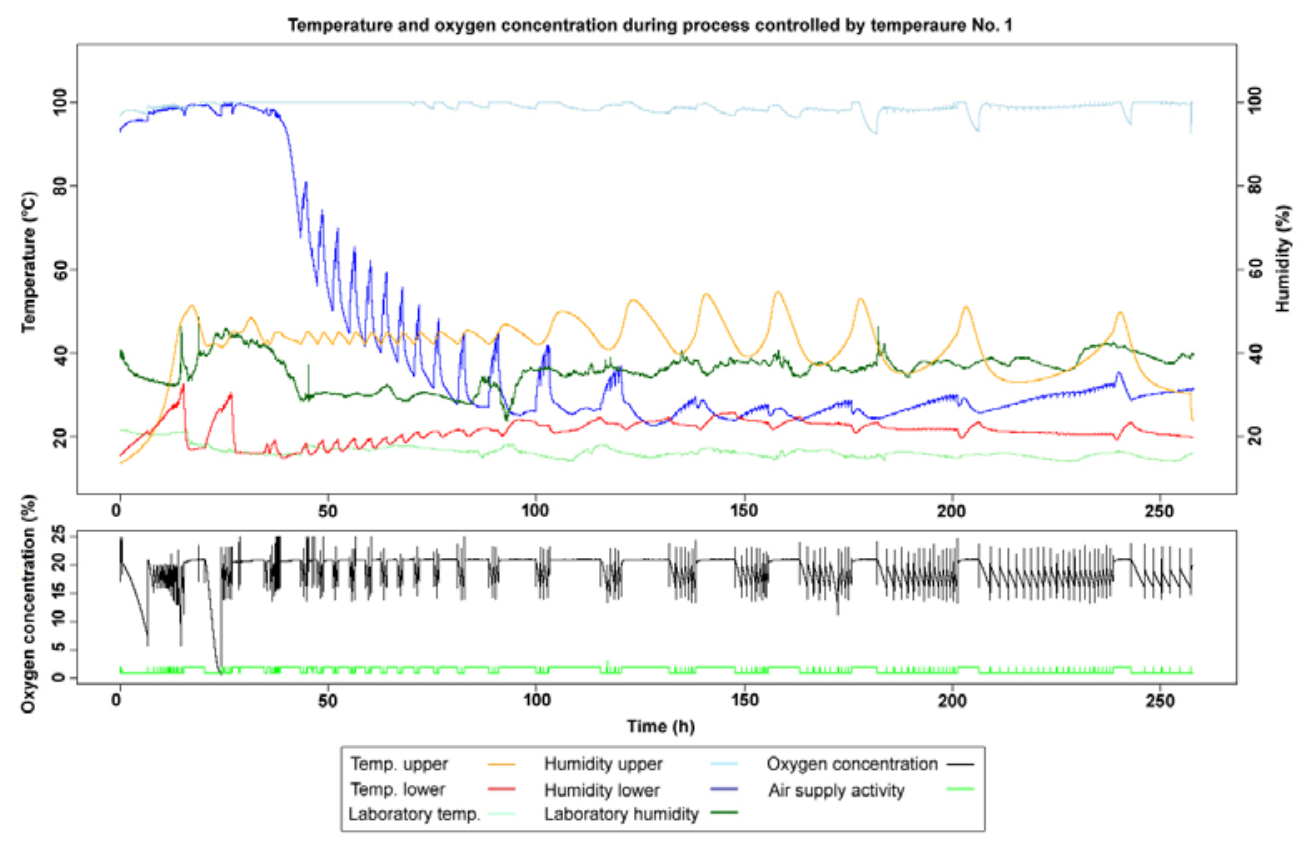

Fig. 5 Temporal dependence of the temperature, relative air humidity and oxygen level measured in the reactor and/or in the lab, temporal dependence of the air supply activity - method in which the temperature was controlled, run No. 1.

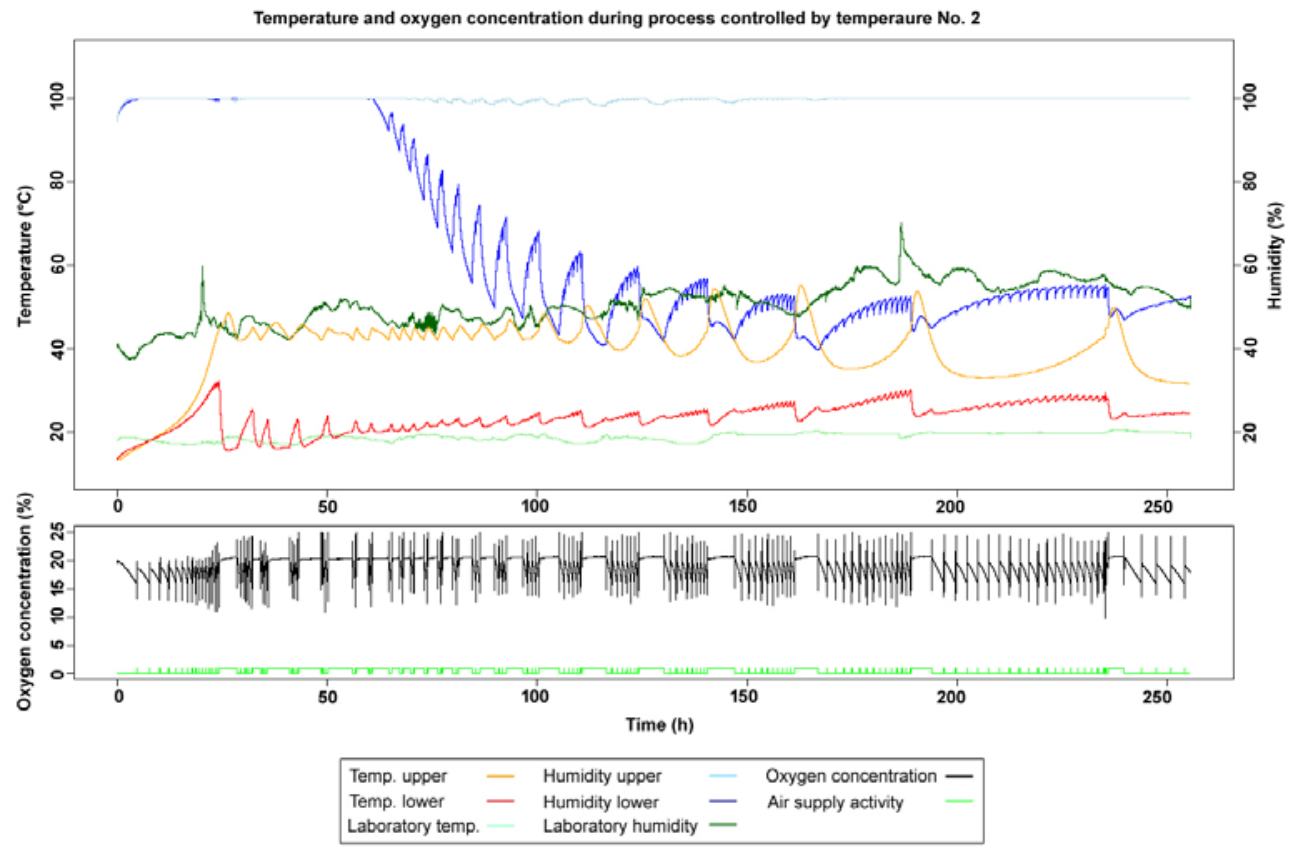

Fig. 6 Temporal dependence of the temperature, relative air humidity and oxygen level measured in the reactor and/or in the lab, temporal dependence of the air supply activity - method in which the temperature was controlled, run No. 2.

humidity recorded in the lower and upper layers are approximately comparable in the middle of the run. Subsequently, the relative humidity in the upper layer began to decrease. Relatively balanced moisture values recorded in Table 2 agree with Fig. 4 This effect may be due to a higher temperature being maintained for longer in the upper layer, which is indicated by the high average temperature and high cumulative temperature recorded in the upper layer. On that account, there was a large difference in cumulative temperature between the lower and the upper layer (Tables 6 and 7). A low temperature in the lower layer and a great difference in temperature between the layers resulted in a reduced moistening of the air flowing through the lower layer. In the upper layer, where the temperature was higher, the air had a greater capacity for absorbing moisture and thus greater desiccation of the upper layer. The high temperature in the upper layer was a result of a high rate of decomposition of organic matter, possibly due to the high organic matter content of dry waste and an optimal concentration of oxygen. The high 
Table 6 Average temperatures.

\begin{tabular}{|l|c|c|c|}
\hline Run & $\begin{array}{c}\text { Average } \\
\text { temperature } \\
\text { of upper layer } \\
\left({ }^{\circ} \mathbf{C}\right)\end{array}$ & $\begin{array}{c}\text { Average } \\
\text { temperature } \\
\text { of lower layer } \\
\left({ }^{\circ} \mathbf{C}\right)\end{array}$ & $\begin{array}{c}\text { Average } \\
\text { difference in } \\
\text { temperature } \\
\left({ }^{\circ} \mathbf{C}\right)\end{array}$ \\
\hline $\begin{array}{l}\text { Temperature } \\
\text { No. 1 }\end{array}$ & 41.30 & 21.28 & 20.02 \\
\hline $\begin{array}{l}\text { Temperature } \\
\text { No. 2 }\end{array}$ & 39.46 & 23.40 & 16.06 \\
\hline Oxygen No. 1 & 49.69 & 33.51 & 16.18 \\
\hline Oxygen No. 2 & 46.43 & 27.00 & 19.44 \\
\hline
\end{tabular}

Table 7 Cumulative temperatures.

\begin{tabular}{|l|c|c|c|}
\hline Run & $\begin{array}{c}\text { Cumulative } \\
\text { temperature } \\
\text { of upper layer } \\
\left({ }^{\circ} \mathbf{C} \cdot \mathbf{s}\right)\end{array}$ & $\begin{array}{c}\text { Cumulative } \\
\text { temperature } \\
\text { of lower layer } \\
\left({ }^{\circ} \mathbf{C} \cdot \mathbf{s}\right)\end{array}$ & $\begin{array}{c}\text { Difference in } \\
\text { Cumulative } \\
\text { temperatures } \\
\left({ }^{\circ} \mathbf{C} \cdot \mathbf{s}\right)\end{array}$ \\
\hline $\begin{array}{l}\text { Temperature } \\
\text { No. } 1\end{array}$ & 7674846 & 3955244 & 3719602 \\
\hline $\begin{array}{l}\text { Temperature } \\
\text { No. 2 }\end{array}$ & 7267152 & 4309049 & 2958103 \\
\hline Oxygen No. 1 & 9063866 & 6112895 & 2950971 \\
\hline Oxygen No. 2 & 8657955 & 5033945 & 3624011 \\
\hline
\end{tabular}

level of decomposition was confirmed by the low value for volatile organic matter in the upper layer in the method in which the concentration of oxygen was controlled, run No. 2 (Table 5). Zawadzka et al. (2010) describe a similar phenomenon.

The differences in the values of the moisture and calorific content are similar in both runs of the method in which the temperature was controlled and run No. 1 in which the oxygen concentration was controlled. In which, the lower the moisture value recorded the higher the calorific value. The exception was the method in which the concentration of oxygen was controlled in run No. 2. Although the moisture content in the lower and upper layers was the same, there was a difference in the calorific values. This may be due to the decrease in organic matter content that resulted from the high rate of decomposition (Table 5).

\section{Conclusions}

Two methods of aeration were compared: in one the oxygen concentration was controlled and in the other temperature was controlled in the upper part of the reactor. A better performance in terms of removal of water and increase in calorific value was achieved using the method in which temperature was controlled. The net energetic balance of the bio drying process was positive for both methods. The method, in which the concentration of oxygen was controlled, was slightly better in terms of the energetic balance. The product, however, is much more dependent on the composition of the dried waste used. Thus, it is suitable only for wastes of known composition.

Differences in temperature, moisture and calorific values recorded during the runs were similar to those reported in the literature. The only exception was the method, in which the concentration of oxygen was controlled, run No. 2. In this case, the opposite was recorded. In the upper layer, there was a lower moisture content and lower relative humidity than in the lower layer. This was probably because of the higher organic matter content of the sample processed. In combination with an optimal concentration of oxygen, the higher organic matter content resulted in a higher rate of decomposition and thus a higher temperature in the upper layer over a longer period of time. This brings us to the important finding that higher organic matter content and aeration regime settings invert the moisture gradient. In the future, this finding could be used to produce homogenous fuel mixtures.

There were differences in the drying efficiency recorded in run No. 1 and run No. 2 in which temperature was controlled. These differences were probably due to a difference in ambient air humidity. The characteristics of the ambient air (mainly humidity) could thus have an important effect on the drying efficiency. Ambient air characteristics are not considered in most studies on the bio drying of MSW.

\section{Acknowledgements}

The research was supported by the Technology Agency of the Czech Republic, project No. SS02030008, programme: Prostředí pro život.

\section{REFERENCES}

Adani F, Baido D, Enrico Calcaterra E, Genevini P (2002) The influence of biomass temperature on biostabilization-biodrying of municipal solid waste. Bioresour Technol 83: 173-179.

Avalos Ramirez A, Godbout S, Léveillée F, Zegan D, Larouche JP (2012) Effect of temperature and air flow rate on carbon and nitrogen compounds changes during the biodrying of swine manure in order to produce combustible biomasses. J Chem Technol Biotechnol 87: 831-836.

Cai L, Chen TB, Gao D, Zheng GD, Liu HT, Pan TH (2013) Influence of forced air volume on water evaporation during sewage sludge bio-drying. Water Res 47: 4767-4773.

Cimpan C, Wenzel H (2013) Energy implications of mechanical and mechanical-biological treatment compared to direct waste-to-energy. Waste Manag 33: 1648-1658.

Colomer-Mendoza FJ, Robles-Martinez F, Herrera-Prats L, Gallardo-Izquierdo A, Bovea MD (2012) Biodrying as a biological process to diminish moisture in gardening and harvest wastes. Environ Dev Sustain 14: 1013-1026.

De Guardia A, Petiot C, Benoist JC, Druilhe C (2012) Characterization and modelling of the heat transfers in a pilot-scale re- 
actor during composting under forced aeration. Waste Manag 32: 1091-1105.

Economopoulos A (2010) Technoeconomic aspects of alternative municipal solid wastes treatment methods. Waste Manag 30: 707-715.

Huiliñir C, Villegas M (2014) Biodrying of pulp and paper secondary sludge: Kinetics of volatile solids biodegradation. Bioresour Technol 157: 206-213.

Sugni M, Calcaterra E, Adani F (2005) Biostabilization-biodrying of municipal solid waste by inverting air-flow. Bioresour Technol 96: 1331-1337.

Vandergheynst JS, Gossett JM, Walker LP (1997) High-solids aerobic decomposition: pilot-scale reactor development and experimentation. Process Biochem 32: 361-365.

Velis CA, Longhurst PJ, Drew GH, Smith R, Pollard SJT (2009) Biodrying for mechanical-biological treatment of wastes: a review of process science and engineering. Bioresour Technol 100: $2747-2761$.
Walker LP, Nock TD, Gossett JM, Vandergheynst JS (1999) The role of periodic agitation and water addition in managing moisture limitations during high-solids aerobic decomposition. Process Biochem 34: 601-612.

Yuan J, Zhang D, Li Y, Li J, Luo W, Zhang H, Wang G, Li G (2018) Effects of the aeration pattern, aeration rate, and turning frequency on municipal solid waste biodrying performance. J Environ Manage 218: 416-424.

Zawadzka A, Krzystek L, Ledakowicz S (2010) Autothermal biodrying of municipal solid waste with high moisture content. Chem Pap 64: 265-268.

Zhang D, Xu Z, Wang G, Huda N, Li G, Luo W (2020) Insights into characteristics of organic matter during co-biodrying of sewage sludge and kitchen waste under different aeration intensities. Environ Technol Innov 20: 101-117.

Zhao L, Gu WM, He PJ, Shao LM (2010) Effect of air-flow rate and turning frequency on bio-drying of dewatered sludge. Water Res 44: 6144-6152. 